\title{
User Error With Diskus and Turbuhaler by Asthma Patients and Pharmacists in Jordan and Australia
}

\author{
Iman A Basheti PhD, Eyad Qunaibi PhD, Sinthia Z Bosnic-Anticevich PhD, Carol L Armour PhD, \\ Samar Khater MSci, Muthana Omar BPharm, and Helen K Reddel PhD
}

\begin{abstract}
BACKGROUND: Use of inhalers requires accurate completion of multiple steps to ensure effective medication delivery. OBJECTIVE: To evaluate the most problematic steps in the use of Diskus and Turbuhaler for pharmacists and patients in Jordon and Australia. METHODS: With standardized inhaler-technique checklists, we asked community pharmacists to demonstrate the use of Diskus and Turbuhaler. We asked patients with asthma to demonstrate the inhaler (Diskus or Turbuhaler) they were currently using. RESULTS: Forty-two community pharmacists in Jordan, and 31 in Australia, participated. In Jordan, 51 asthma patients demonstrated use of Diskus, and 40 demonstrated use of Turbuhaler. In Australia, 53 asthma patients demonstrated use of Diskus, and 42 demonstrated use of Turbuhaler. RESULTS: The pharmacists in Australia had received inhalertechnique education more recently than those in Jordan $(P=.03)$. With Diskus, few pharmacists in either country demonstrated correct technique for step 3 (exhale to residual volume) or step 4 (exhale away from the device), although there were somewhat fewer errors in Australia than Jordan (16\% vs $0 \%$ in step $3, P=.007$, and $20 \%$ vs $0 \%$ in step $4, P=.003$ via chi-square test). With Turbuhaler there were significant differences between the pharmacists from Australia and Jordan, mainly in step 2 (hold the device upright while loading, $45 \%$ vs $2 \%$ correct, $P<.001$ ). Few of the patients had received inhaler-technique education in the previous year. The patients made errors similar to those of the pharmacists in individual steps with Diskus and Turbuhaler. The essential steps with Diskus were performed correctly more often by the Jordanian patients, and with Turbuhaler by the Australian patients. CONCLUSIONS: Despite differences in Jordan's and Australia's health systems, pharmacists from both Australia and Jordan had difficulty with the same Diskus and Turbuhaler steps. In both countries, the errors made by the asthma patients were similar to those made by the pharmacists. Key words: inhaler technique; asthma management; pharmacists; asthma education. [Respir Care 2011;56(12):1916-1923. (C) 2011 Daedalus Enterprises]
\end{abstract}

\section{Introduction}

Asthma has no cure; however, with appropriate management, control of the disease can be achieved. ${ }^{1}$ The inflammatory changes of asthma are primarily found lo-

\footnotetext{
Drs Basheti, Qunaibi, and Omar, and Mr Khater are affiliated with the Faculty of Pharmacy, Applied Science Private University, Amman, Jordan. Dr Bosnic-Anticevich is affiliated with the Faculty of Pharmacy; Drs Reddel and Armour are affiliated with the Woolcock Institute of Medical Research, University of Sydney, Sydney, New South Wales, Australia.
}

This study was partly supported by a grant from the Applied Science Private University, Amman, Jordan. cally in the airways, so it is logical to use the inhalation route for treatment. Currently, several types of inhaler are used to deliver asthma controller medications, primarily pressurized metered-dose inhaler and dry powder inhaler (eg, Diskus [GlaxoSmithKline] and Turbuhaler [AstraZeneca]). Although these inhalers were pioneering in their

\footnotetext{
Dr Basheti presented a version of this paper at the 16th Social Pharmacy Workshop held in Lisbon, Portugal, August 2, 2010.

Correspondence: Iman A Basheti PhD, Faculty of Pharmacy, Clinical Pharmacy, and Therapeutics. Applied Science Private University, Amman, Jordan 11931. E-mail: ibasheti@usyd.edu.au.
}

DOI: $10.4187 /$ respcare.01205 
designs, ${ }^{2}$ their use is not straightforward. As with pressurized metered-dose inhaler, both Diskus and Turbuhaler require a series of maneuvers in a specific order to deliver drug into the airways. ${ }^{3,4}$

Judging by the many studies that have shown poor skills with the individual steps required for inhaler use, ${ }^{5-11}$ it appears that the importance of correctly following the steps has often not been given appropriate attention by patients or healthcare professionals. Suboptimal inhaler technique is associated with increased asthma instability, ${ }^{12}$ and because of perceived lack of effectiveness of the medication, to poor medication adherence, ${ }^{13,14}$ which can lead to doctors prescribing higher doses of controller medication, leading to adverse effects and higher costs. ${ }^{15,16}$

In many countries, pharmacists are responsible for the physical supply of medications to the patient and hence pharmacists are the last healthcare professionals the patients see before they go home to use their inhalers. Pharmacists can make use of this opportunity by assessing and educating patients on inhaler technique, both initially and at subsequent dispensing. However, many pharmacists do not correctly demonstrate the steps and hence are not skilled in educating their patients on inhaler technique. ${ }^{10,17}$ Incorrect demonstration of the steps by a pharmacist may be the source of incorrect inhaler technique by patients. Healthcare systems and health-professional education differ around the globe. To our knowledge, no previous study has compared the inhaler steps performed incorrectly by pharmacists and by patients, nor has there been a comparison of inhaler-technique skills among pharmacists and patients from different cultural backgrounds and healthcare systems. We compared Diskus and Turbuhaler inhaler technique among pharmacists and asthma patients in Jordan and Australia, to identify the steps that are most problematic.

\section{Methods}

This study was performed at the Applied Science Private University, Amman, Jordan, and University of Sydney, Sydney, Australia, and approved by the respective ethics committees.

\section{Study Design}

We report the individual inhaler-technique steps that were performed correctly/incorrectly by pharmacists and asthma patients in a cross-sectional study in Jordan in 2009, and in Australia in 2004, during baseline assessment in an inhaler-technique intervention study. We previously reported the proportion of Australian pharmacists and patients with correct technique, ${ }^{4}$ and their inhaler-technique scores. ${ }^{9}$ The methods of both studies are given below. The Australia data used in the present comparisons were from
Table 1. Checklists for Assessment of Diskus and Turbuhaler Technique $^{*}$

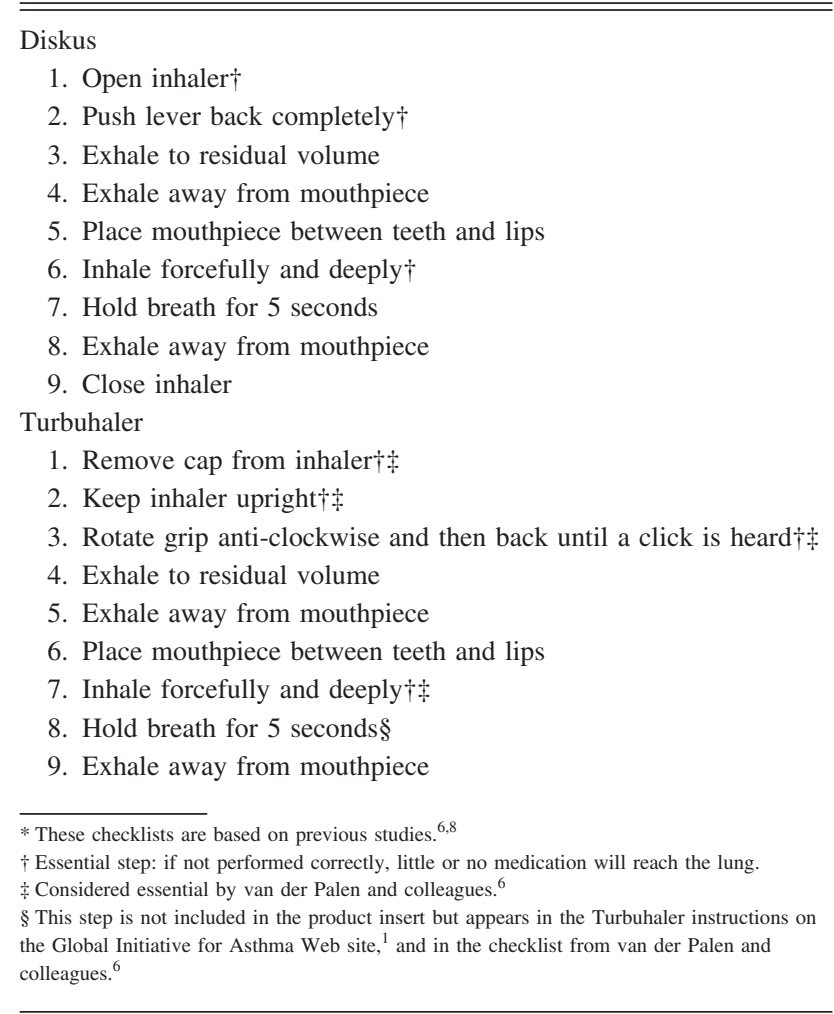

the baseline assessment of pharmacists and patients during a 6-month single-blind cluster randomized study of inhaler-technique education. ${ }^{4,9}$ To maintain blinding, and with the consent of the ethics committee, the pharmacists and patients were advised that the study was about ways to improve asthma management.

\section{Inhaler-Technique Assessment}

Based on published Diskus and Turbuhaler inhalertechnique steps checklists (Table 1), and without receiving any inhaler-technique education immediately before the study, pharmacists and patients in Jordan and Australia underwent Diskus and Turbuhaler inhaler-technique assessment. ${ }^{4,8-10,18}$ Both the Diskus and Turbuhaler checklists comprise 9 steps, of which 3 steps and 4 steps, respectively, are essential (see Table 1). GlaxoSmithKline provided placebo Diskus inhalers, and AstraZeneca provided placebo Turbuhaler inhalers.

\section{Pharmacists in Jordan}

We randomly selected and invited community pharmacists in Amman, Jordan, to participate in a study that involved attending a 3-hour educational workshop on asthma 
Table 2. Demographics of the Community Pharmacists

\begin{tabular}{lcc}
\hline \hline & $\begin{array}{c}\text { Jordan } \\
(n=42)\end{array}$ & $\begin{array}{c}\text { Australia } \\
(n=31)\end{array}$ \\
\hline Male, no. (\%) & $29(69)$ & $17(55)$ \\
Age (mean \pm SD y) & $33.6 \pm 8.4$ & $37.0 \pm 10.5$ \\
Years in practice (mean \pm SD y) & $11.4 \pm 8.2$ & $13.2 \pm 10.7$ \\
\hline
\end{tabular}

management. We then asked the pharmacists who participated in the workshop to show how they would demonstrate the use of Diskus and Turbuhaler to patients, and assessed their performance of the inhaler-technique steps against the relevant checklist. The inclusion criteria were that the pharmacist was practicing at a pharmacy located within Amman, agreed to demonstrate inhaler technique, and was not involved in any other clinical study.

\section{Asthma Patients in Jordan}

We invited patients with asthma as they were leaving an out-patient clinic in Amman with a Diskus or Turbuhaler prescription. With placebo inhalers, one trained pharmacist assessed their Diskus or Turbuhaler technique. The inclusion criteria were: age $\geq 14$ years, doctor-diagnosed asthma, and using inhaled corticosteroids via Diskus or Turbuhaler at the same dose for at least one month. We excluded patients who did not self-administer their medication, did not speak or understand Arabic, or were involved in another clinical study.

\section{Pharmacists in Australia}

The inclusion criteria were: practicing at a pharmacy in the Sydney metropolitan area, with at least one pharmacist assistant present at all times, and not involved in any other clinical study. We excluded pharmacists who were not able to attend the 3-hour study workshop or to commit to the 6-month follow-up study. We assessed the pharmacists on their Diskus and Turbuhaler technique at the beginning of the workshop. After this baseline assessment we randomized the pharmacists to receive one of two workshops. The control group were trained to assess asthma control and to teach patients how to measure and monitor peak flow. The intervention group received that same education plus assessment of and education about Diskus and Turbuhaler technique. All the intervention-group pharmacists were able to demonstrate correct technique of both inhalers before they commenced recruiting patients. The strategy used to educate pharmacists about inhaler technique was previously evaluated for its efficacy and was reported elsewhere. ${ }^{8}$

\section{Asthma Patients in Australia}

Participating pharmacists recruited asthma patients who came to their community pharmacies with a prescription for Diskus or Turbuhaler. The inclusion criteria were: age $\geq 14$ years, doctor-diagnosed asthma, and using inhaled corticosteroids via Diskus or Turbuhaler at the same dose for at least one month. We excluded patients who did not self-administer their medication, did not speak or understand English, were not able to return for all visits, or were involved in another clinical study. One pharmacist researcher (IAB) assessed all the patients recruited by the control-group pharmacists. The intervention-group pharmacists assessed their own patients. As previously reported, the accuracy of inhaler-technique assessment by the intervention-group pharmacists was independently validated by one researcher (IAB). ${ }^{9}$

\section{Data Analysis}

Data were analyzed with statistics software (SPSS 17, SPSS, Chicago, Illinois). All the analyses are of assess-

Table 3. Inhaler Education of the Community Pharmacists*

\begin{tabular}{|c|c|c|c|c|}
\hline & \multicolumn{2}{|c|}{$\begin{array}{l}\text { Jordan } \\
(n=42)\end{array}$} & \multicolumn{2}{|c|}{$\begin{array}{l}\text { Australia } \\
(n=31)\end{array}$} \\
\hline & Diskus & Turbuhaler & Diskus & Turbuhaler \\
\hline Received previous education on device, no. (\%) & $42(100)$ & $41(98)$ & $29(94)$ & $28(90)$ \\
\hline Years since previous inhaler education (mean \pm SD y) & $5.3 \pm 5.3$ & $5.7 \pm 5.1$ & $2.6 \pm 2.4 \dagger$ & $3.6 \pm 3.3$ \\
\hline \multicolumn{5}{|l|}{ Source of previous device education, no. (\%) } \\
\hline Pharmacy school & $9(21)$ & $12(29)$ & $8(26)$ & $10(32)$ \\
\hline Continuing education program & $7(17)$ & $6(14)$ & $6(19)$ & $8(26)$ \\
\hline Manufacturer representative & $9(21)$ & $8(19)$ & $19(61) \ddagger$ & $18(58)$ \\
\hline Self-taught & $14(33)$ & $16(38)$ & $14(45)$ & $13(42)$ \\
\hline $\begin{array}{l}* \text { The respondent could select more than one source of device education. } \\
\dagger P=.03 \text { for Jordan vs Australia. } \\
\ddagger P=.001 \text { for Jordan vs Australia. }\end{array}$ & & & & \\
\hline
\end{tabular}




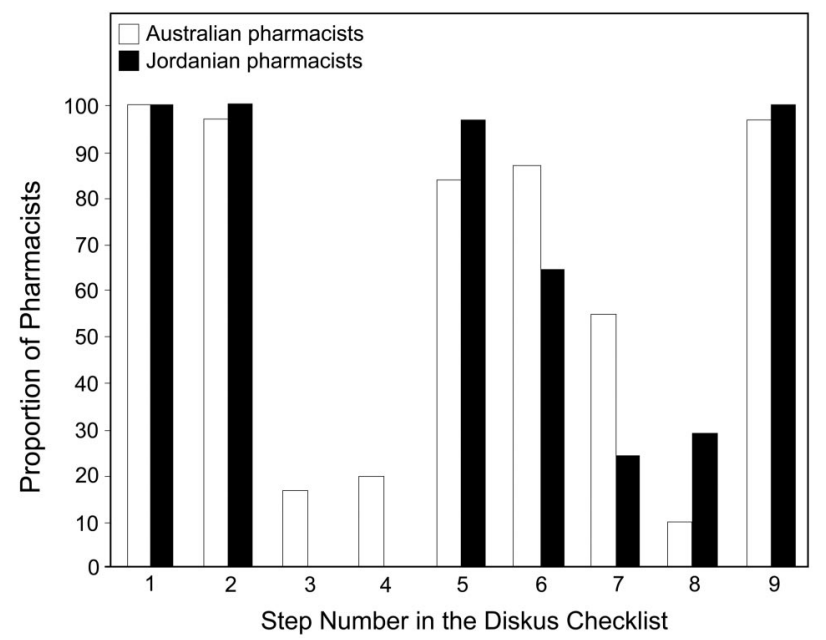

Fig. 1. Proportion of pharmacists from Jordan $(n=42)$ and Australia $(n=31)$ who correctly performed the individual steps with Diskus.

ments prior to any inhaler education from us. We compared the proportions of pharmacists and patients who correctly demonstrated each individual step in the checklist, between groups (pharmacists vs patients) and countries (Jordan vs Australia) with Pearson's chi-square test. Differences with $P<.05$ were considered statistically significant.

\section{Results}

\section{Pharmacists' Demographics and Inhaler-Technique Education}

In Jordan, 120 pharmacists were approached, and 73 agreed to attend the workshop, but 31 of those declined to demonstrate inhaler technique, leaving a sample size of 42 pharmacists. In Australia, 120 pharmacists were approached, and 31 attended the workshop, during which their inhaler technique was assessed. ${ }^{10}$

Table 2 shows the pharmacists' demographic data, and Table 3 describes their inhaler education. There were no significant differences in sex, age, or years in community pharmacy practice. The mean reported time since previous inhaler device education was shorter among the Australian pharmacists, and a significantly higher proportion of the Australian pharmacists had received previous education on Diskus and Turbuhaler technique from manufacturer representatives.

\section{Pharmacists' Diskus Performance}

Figure 1 shows the percentages of pharmacists who correctly demonstrated the steps. The most frequent errors were failing to exhale fully (step 3), not exhaling away

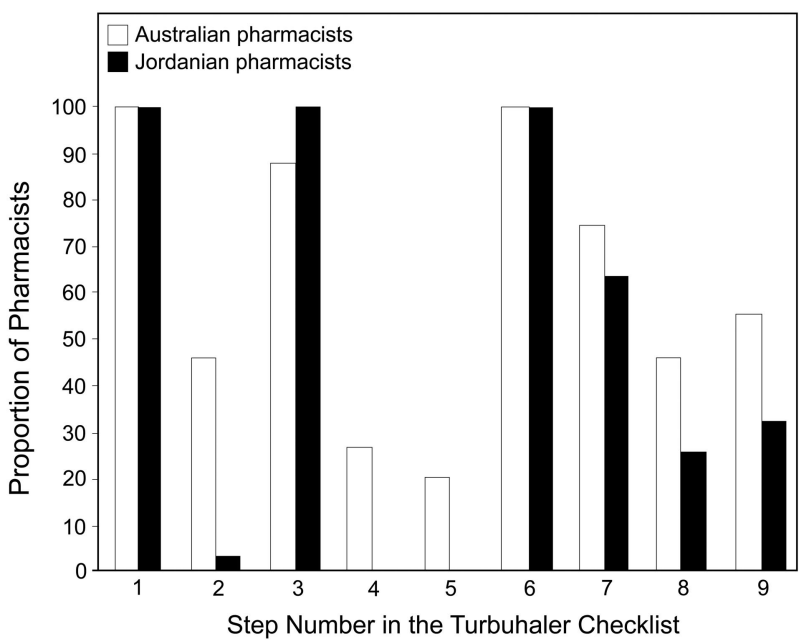

Fig. 2. Proportion of pharmacists from Jordan $(n=42)$ and Australia $(n=31)$ who correctly performed the individual steps with Turbuhaler.

from the mouthpiece before (step 4) or after inhalation (step 8), and not holding the breath following inhalation (step 7). Most of the pharmacists from both countries did not correctly perform steps 7 or 8 . Although more Australian than Jordanian pharmacists correctly demonstrated steps $3(P=.007)$ and $4(P=.003)$, the proportion who correctly demonstrated these steps was low in both countries (see Fig. 1). Significantly more Jordanian pharmacists correctly performed step 5 (mouthpiece between teeth and lips) $(P=.007)$, but over $80 \%$ of pharmacists from both countries performed this step correctly (see Fig. 1). Eighty-four percent of the Australian pharmacists correctly performed the 3 essential Diskus steps (steps 1,2, and 6), compared to $64 \%$ of the Jordanian pharmacists, but that difference was not significant $(P=.064$ via chi-square test).

\section{Pharmacists' Turbuhaler Performance}

A high proportion of pharmacists from both countries made errors on steps in the Turbuhaler checklist (Fig. 2). There were significant differences between the Australian and Jordanian pharmacists. Almost none of the Jordanian pharmacists correctly performed step 2 (keep inhaler upright), step 4 (exhale fully), or step 5 (exhale away from mouthpiece $)$, compared to $45 \%(P<.001), 26 \%(P=.001)$, and $19 \%(P=.003)$, respectively, among the Australian pharmacists. Many pharmacists from both countries also made errors in step 8 (hold breath) and step 9 (exhale away from mouthpiece), but the differences between countries were not significant (see Fig. 2). None of the Jordanian pharmacists correctly performed all 4 essential Turbuhaler steps $(1,2,3$, and 7$)$, compared to $35 \%$ of the Australian pharmacists $(P=.002)$. 
Table 4. Demographics of the Asthma Patients

\begin{tabular}{|c|c|c|c|c|}
\hline & \multicolumn{2}{|c|}{ Jordan } & \multicolumn{2}{|c|}{ Australia } \\
\hline & $\begin{array}{c}\text { Diskus } \\
\text { Users } \\
(n=51)\end{array}$ & $\begin{array}{c}\text { Turbuhaler } \\
\text { Users } \\
(n=40)\end{array}$ & $\begin{array}{c}\text { Diskus } \\
\text { Users } \\
(n=53)\end{array}$ & $\begin{array}{c}\text { Turbuhaler } \\
\text { Users } \\
(n=42) \\
\end{array}$ \\
\hline Male, no. $(\%)$ & $17(33)$ & $12(30)$ & $25(47)$ & $14(33)$ \\
\hline Age (mean $\pm \mathrm{SD}$ y) & $43.1 \pm 15.2$ & $41.8 \pm 14.3$ & $42.4 \pm 19.2$ & $46.9 \pm 19.6$ \\
\hline Duration of inhaled corticosteroid use (mean \pm SD y) & $3.2 \pm 1.2$ & $2.8 \pm 1.3$ & $1.9 \pm 1.9$ & $2.5 \pm 3.2$ \\
\hline
\end{tabular}

Table 5. Inhaler Technique Education of the Asthma Patients*

\begin{tabular}{|c|c|c|c|c|c|c|}
\hline & \multicolumn{2}{|c|}{ Jordan } & \multicolumn{2}{|c|}{ Australia } & \multicolumn{2}{|c|}{$P($ Jordan vs Australia $) \dagger$} \\
\hline & $\begin{array}{c}\text { Diskus } \\
\text { Users } \\
(n=51)\end{array}$ & $\begin{array}{c}\text { Turbuhaler } \\
\text { Users } \\
(n=40)\end{array}$ & $\begin{array}{c}\text { Diskus } \\
\text { Users } \\
(n=53)\end{array}$ & $\begin{array}{c}\text { Turbuhaler } \\
\text { Users } \\
(n=42)\end{array}$ & $\begin{array}{c}\text { Diskus } \\
\text { Users }\end{array}$ & $\begin{array}{c}\text { Turbuhaler } \\
\text { Users }\end{array}$ \\
\hline $\begin{array}{l}\text { Inhaler education received in the previous } 12 \text { months, } \\
\text { no. (\%) }\end{array}$ & $8(16)$ & $10(25)$ & $12(23)$ & $9(21)$ & .39 & .66 \\
\hline $\begin{array}{l}\text { Education included verbal and physical demonstration, } \\
\text { no. }(\%)\end{array}$ & $8(16)$ & $12(30)$ & $20(38)$ & $12(29)$ & .01 & .83 \\
\hline \multicolumn{7}{|l|}{ Source of inhaler education, no. (\%) } \\
\hline General practitioner & $17(33)$ & $18(45)$ & $41(77)$ & $33(79)$ & $<.001$ & .003 \\
\hline Pharmacist & $3(6)$ & $2(5)$ & $12(23)$ & $12(29)$ & .02 & .005 \\
\hline Specialist physician & $38(75)$ & $28(70)$ & $6(11)$ & $7(17)$ & $<.001$ & $<.001$ \\
\hline Hospital & $26(51)$ & $18(45)$ & $3(6)$ & $3(7)$ & $<.001$ & $<.001$ \\
\hline Self-education from product information & $1(2)$ & $1(3)$ & $10(19)$ & $8(19)$ & .006 & .02 \\
\hline
\end{tabular}

\section{Patients' Demographics and Inhaler-Technique Education}

In Jordan, 60 Diskus and 60 Turbuhaler patients were approached, and 51 and 40 , respectively, agreed to participate. In Australia, 53 Diskus patients and 42 Turbuhaler patients participated, but the number of patients approached is not known. There were no significant differences in age or sex of the Australian and Jordanian groups (Table 4). The Australian patients had been using their Diskus controller medication for significantly shorter than the Jordanian patients.

There were significant differences between the Jordanian and Australian patients in the sources of inhaler-technique education (Table 5). Significantly more Australian patients had received education from a general practitioner or pharmacist, whereas significantly more Jordanian patients were educated by a specialist or at a hospital. The proportion of patients who reported that they had taught themselves how to use the inhaler from the product information was low in both countries.

\section{Patients' Diskus Performance}

The pattern of patient errors with Diskus (Fig. 3) was similar to that for pharmacists. The most problematic steps for patients from both countries were steps $3,4,7$, and 8 , although more Australian patients correctly performed step $3(P=.002)$, step $4(P<.001)$, and step $7(P=.002)$, and more Jordanian patients correctly performed step 5 $(P=.01)$ and step $9(P=.004)$. Significantly more Jordanian patients than Australian patients performed the essential Diskus steps correctly ( $80 \%$ vs $57 \%, P=.009$ ).

\section{Patients' Turbuhaler Performance}

The majority of patients from both countries incorrectly performed step 2 (keep inhaler upright), and a high proportion had errors in steps 4,5 , and 8 (Fig. 4). Although few patients from either country correctly performed steps 4 and 5, the rates were somewhat higher among the Australian patients (step 4, $P=.002$; step 5, $P<.001$ ). None of the Jordanian patients correctly performed the essential 


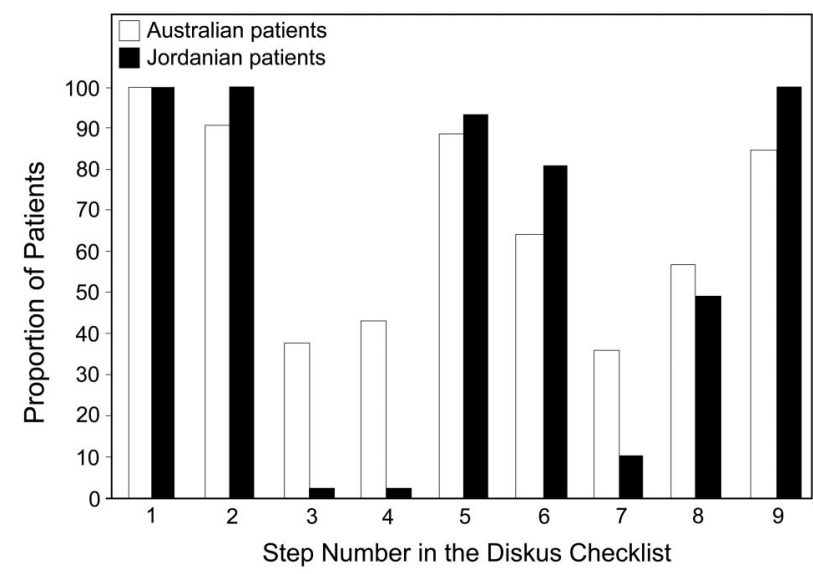

Fig. 3. Proportion of patients from Jordan $(n=51)$ and Australia $(n=53)$ who correctly performed the individual steps with Diskus.

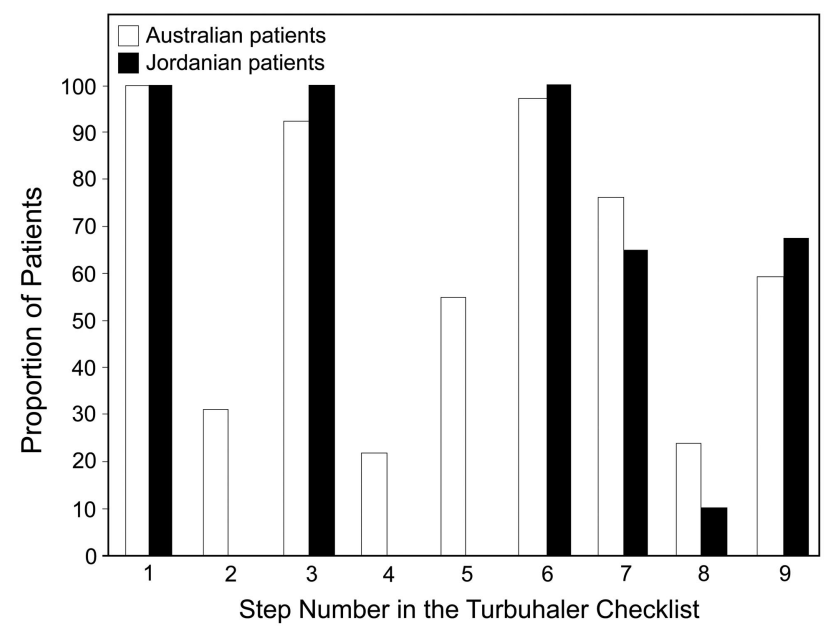

Fig. 4. Proportion of patients from Jordan $(n=40)$ and Australia $(n=42)$ who correctly performed the individual steps with Turbuhaler.

Turbuhaler steps, compared to $29 \%$ of the Australian patients $(P<.001)$.

\section{Discussion}

Despite differences in the healthcare systems and health education between Jordan and Australia, certain of the Diskus and Turbuhaler steps were problematic in both countries. There were similar rates of error in Jordan and Australia, and the rates were similar between the patients and pharmacists. This suggests that these problematic steps are device-specific and not a result of cultural or healtheducation backgrounds. In addition, the fact that there were similar patterns of incorrect technique in both pharmacists and patients in both countries suggests that incorrect inhaler technique among pharmacists might contribute to similar problems in patients. Hence, regardless of the med- ical or national background, the inhaler-technique education of health professionals needs to be actively addressed before we can expect patient education to be effective.

These results are probably not due to differences in delivery of the inhalers between Jordan and Australia. In both countries a doctor's prescription is needed to obtain Diskus or Turbuhaler, so patients from both countries may receive inhaler-technique education from doctors and/or pharmacists. The inhaler use instructions in the product leaflets are standardized in both countries.

However, there were important differences between Jordan and Australia in the sources of patient education. Significantly more Jordanian patients reported learning inhaler technique at hospitals or from specialists, whereas the Australian patients reported the most education from general practitioners and pharmacists. While these differences may reflect the different sites of patient-recruitment (hospital out-patient clinic in Jordan, community pharmacies in Australia), they may also reflect differences in the health systems for asthma care between the 2 countries. Patients with asthma in Jordan have ready access to community or hospital specialists, whereas in Australia, asthma is largely managed by general practitioners, and only a small proportion of patients visit a specialist. ${ }^{19}$ From the present results, pharmacists seem to have a more active role in patient inhaler-technique education in Australia than in Jordan.

Although similar steps were problematic in both populations, the Australian pharmacists generally demonstrated better technique. As a faculty member in both Jordan and Australia, one of us (IAB) has observed a greater emphasis on teaching inhaler device use to undergraduate pharmacy students in Australia (at the University of Sydney) than in Jordan (at the Applied Science Private University). This may have contributed to the observed differences in pharmacist technique, although the pharmacists also came from other universities. While pharmaceutical industry representatives are important in both countries, they had a much greater role in pharmacist education in Australia than in Jordan, which may have contributed to better inhaler technique among the Australian pharmacists; this highlights the importance of pharmaceutical industry representatives correctly demonstrating inhaler use. ${ }^{10}$

One of the strengths of this study was that we used the same checklists with patients and pharmacists, in both Jordan and Australia. Many studies have assessed patients' and pharmacists' inhaler technique, but the large differences in the proportions of incorrect inhaler technique reported from various countries could have been due to the variety of checklists used in those studies. ${ }^{20-22}$ For example, previous studies have reported that Diskus technique was correctly performed by $13 \%(n=54)$ of Diskus users in Australia, ${ }^{10}$ and by $93 \%(n=103)$ of Diskus users in Jordan. ${ }^{23}$ However, that difference is not surprising, given 
that Basheti et al ${ }^{10}$ used a 9-step checklist, whereas Khassawneh et al23 used a 3 -step checklist. The fewer steps in a checklist, the higher the probability that a patient will be classified as having correct technique.

We followed strict process measures in the present study to maintain consistent inhaler-technique evaluation over time and between countries. We invested detailed attention to the study design to ensure good inter-rater reliability (agreement between the scores given by different assessors for the same subject), which can be a cause of inaccuracy in this type of assessment. Observer bias was minimized with common training of the observers, followed by assessment, and use of a checklist that precisely lists detailed steps. ${ }^{24,25}$

Limitations to this study include the above-mentioned differences in patient recruitment, the fact that patients were not randomly selected, and in the relationship between pharmacists and patients. In Australia, the participating pharmacists recruited customers to whom they might have previously provided education in the pharmacy, whereas in Jordan the patients were recruited from established asthma clinics by one pharmacist researcher, so there was no professional relationship between the patients and the participating pharmacists. However, we do not think the different settings between the 2 countries affect the generalizability of the results. Another limitation is that the studies were not conducted at the same time, and we cannot exclude the possibility that this may have affected our results.

Although the problematic steps were similar in the 2 populations, the Australian pharmacists demonstrated better technique in the essential steps than did the Jordanian pharmacists (Diskus 64\% in Jordan vs $84 \%$ in Australia, Turbuhaler 0\% in Jordan vs 35\% in Australia). The fact that many pharmacists from Jordan refused to demonstrate technique may suggest that poor technique was an even greater problem than we observed. Further, more Australian patients than Jordanian patients reported receiving inhaler-technique education from their pharmacists, so this study underlines the necessity to provide inhaler-technique education not only to patients, but also to all people likely to teach inhaler technique to patients: specialists, general practitioners, pharmacists, and nurses, depending on the national health organization. We previously reported methods that are effective in educating pharmacists or patients on correct inhaler technique. ${ }^{4,10,11}$

There was considerable variation in the accuracy of performance of individual inhaler-technique steps. One of the most common problems with Turbuhaler was failure to hold it upright while rotating the base, a step that is essential for loading the full dose (step 2 correctly performed by $31 \%$ in Australia vs $0 \%$ in Jordan). Other studies have reported that step 2 was performed correctly by $69 \%^{6}$ to $88 \%{ }^{5}$ of patients. Ekedahl ${ }^{26}$ reported that even after one year of an open study aimed at correcting Turbuhaler technique by demonstration, many patients (33\%) did not hold the Turbuhaler upright while loading the device. Turbuhaler loading was correctly performed less often than was Diskus loading (Diskus $91 \%$ vs Turbuhaler $31 \%$ in Australia, and Diskus $100 \%$ vs Turbuhaler 0\% in Jordan), which supports the findings of previous studies. ${ }^{6,27}$ Hence, healthcare professionals should pay more attention when assessing and educating patients on the Turbuhaler loading maneuver. Since the optimal biomechanical position of the forearm for supination/pronation (the maneuver required for step 3) may contribute to the Turbuhaler being held at an angle during loading, we teach Turbuhaler users to place the base of the Turbuhaler on a flat surface for the loading step, as a visual mnemonic to ensure that it is upright.

Few patients held their breath after using Diskus (Australia 36\%, Jordan 10\%) or Turbuhaler (Australia 24\%, Jordan 10\%). Previous studies have found wide ranges in the proportions of patients who do this step correctly with Diskus (47-94\%) and Turbuhaler (53-94\%).6,27 While many published checklists contain the breath-hold instruction, it does not appear in the manufacturer's Turbuhaler instructions.

Failure to inhale forcefully and deeply was also a problem in the patients we studied, as in the majority of previous studies. ${ }^{24,27}$ Kamps reported that this step is the most problematic with asthmatic children. ${ }^{28}$

Our results on the pharmacists' inhaler technique were similar to those reported in other studies of Diskus and Turbuhaler 17,29,30; however, the very low proportion of pharmacists who demonstrated correct performance of individual steps in the study by Chopra and Oprescu might have been partly due to the fact that they combined items into 6-point checklists. ${ }^{30}$

\section{Conclusions}

There were similar Diskus and Turbuhaler technique problems among pharmacists and patients in Jordan and Australia, despite markedly different health systems and inhaler education between the 2 countries. Awareness of the most problematic steps may help educators concentrate their efforts on these steps during inhaler education. The finding of consistent problems with certain steps should prompt the manufacturers to field test early in the development of new inhalers, to ensure that future inhalers will be easier to teach and use.

\section{REFERENCES}

1. Global Initiative for Asthma (GINA). Global strategy for asthma management and prevention. Updated 2010. http://www.ginasthma. org/pdf/GINA_Report_2010.pdf. Accessed October 11, 2011. 
2. Smith IJ, Parry-Billings M. The inhalers of the future? A review of dry powder devices on the market today. Pulm Pharmacol Ther 2003;16(2):79-95.

3. Newman SP, Pavia D, Moren F, Sheahan NF, Clarke SW. Deposition of pressurised aerosols in the human respiratory tract. Thorax 1981;36(1):52-55.

4. Basheti IA, Reddel HK, Armour CL, Bosnic-Anticevich SZ. Improved asthma outcomes with a simple inhaler technique intervention by community pharmacists. J Allergy Clin Immunol 2007;119(6): 1537-1538.

5. van der Palen J, Klein JJ, Kerkhoff AH, van Herwaarden CL. Evaluation of the effectiveness of four different inhalers in patients with chronic obstructive pulmonary disease. Thorax 1995;50(11):11831187.

6. van der Palen J, Klein JJ, Schildkamp AM. Comparison of a new multidose powder inhaler (Diskus/Accuhaler) and the Turbuhaler regarding preference and ease of use. J Asthma 1998;35(2):147-152.

7. Ronmark E, Jogi R, Lindqvist A, Haugen T, Meren M, Loit HM, et al. Correct use of three powder inhalers: comparison between Diskus, Turbuhaler, and Easyhaler. J Asthma 2005;42(3):173-178.

8. Basheti IA, Reddel HK, Armour CL, Bosnic-Anticevich SZ. Counseling about turbuhaler technique: needs assessment and effective strategies for community pharmacists. Respir Care 2005;50(5):617-623.

9. Basheti IA, Armour CL, Bosnic-Anticevich SZ, Reddel HK. Evaluation of a novel educational strategy, including inhaler-based reminder labels, to improve asthma inhaler technique. Patient Educ Couns 2008;72(1):26-33.

10. Basheti IA, Reddel HK, Armour CL, Bosnic-Anticevich SZ. Longterm maintenance of pharmacists' inhaler technique: applying focused educational tools. Am J Pharm Edu 2007;73:32.

11. Toumas M, Basheti IA, Bosnic-Anticevich SZ. Comparison of smallgroup training with self-directed internet-based training in inhaler techniques. Am J Pharm Educ 2009;73(5):85.

12. Giraud V, Roche N. Misuse of corticosteroid metered-dose inhaler is associated with decreased asthma stability. Eur Respir J 2002;19(2): 246-251.

13. Rau JL. Determinants of patient adherence to an aerosol regimen. Respir Care 2005;50(10):1346-1356.

14. Barnes PJ. Achieving asthma control. Curr Med Res Opin 2005; 21(Suppl 4):S5-S9.

15. Foster JM, Aucott L, van der Werf RH, van der Meijden MJ, Schraa G, Postma DS, et al. Higher patient perceived side effects related to higher daily doses of inhaled corticosteroids in the community: a cross-sectional analysis. Respir Med 2006;100(8):1318-1336.

16. Fink JB, Rubin BK. Problems with inhaler use: a call for improved clinician and patient education. Respir Care 2005;50(10):1360-1374.

17. Kesten S, Zive K, Chapman KR. Pharmacist knowledge and ability to use inhaled medication delivery systems. Chest 1993;104(6):17371742.
18. Basheti IA, Armour CL, Reddel HK, Bosnic-Anticevich SZ. Innovative asthma education and management by community pharmacists. In: Ortiz M, Rubio C, editors. Educational evaluation: 21st century issues and challenges. Hauppauge: Nova Science Publishers; September 2008.

19. Australian Centre for Asthma Monitoring. Asthma in Australia 2008. AIHW Asthma Series No. 3 Cat. ACM 14. Canberra: Australian Institute of Health and Welfare; 2008. http://www.asthmamonitor ing.org/AinA08_html/Index.htm. Accessed October 11, 2011.

20. Brocklebank D, Ram F, Wright J, Barry P, Cates C, Davies L, et al. Comparison of the effectiveness of inhaler devices in asthma and chronic obstructive airways disease: a systematic review of the literature. Health Technol Assess 2001;5(26):1-149.

21. Molimard M, Raherison C, Lignot S, Depont F, Abouelfath A, Moore $\mathrm{N}$. Assessment of handling of inhaler devices in real life: an observational study in 3811 patients in primary care. J Aerosol Med 2003;16(3):249-254.

22. Moore AC, Stone S. Meeting the needs of patients with COPD: patients' preference for the Diskus inhaler compared with the Handihaler. Int J Clin Pract 2004;58(5):444-450.

23. Khassawneh BY, Al-Ali MK, Alzoubi KH, Batarseh MZ, Al-Safi SA, Sharara AM, et al. Handling of inhaler devices in actual pulmonary practice: metered-dose inhaler versus dry powder inhalers. Respir Care 2008;53(3):324-328.

24. Epstein S, Maidenberg A, Hallett D, Khan K, Chapman KR. Patient handling of a dry-powder inhaler in clinical practice. Chest 2001; 120(5):1480-1484.

25. O'Connell MB, Hewitt JM, Lackner TE. Consistency of evaluators assessing inhaler technique. Ann Allergy 1991;67(6):603-608.

26. Ekedahl A. Open-ended questions and show-and-tell: a way to improve pharmacist counseling and patients' handling of their medicines. J Clin Pharm Ther 1996;21(2):95-99.

27. Melani AS, Zanchetta D, Barbato N, Sestini P, Cinti C, Canessa PA, et al. Inhalation technique and variables associated with misuse of conventional metered-dose inhalers and newer dry powder inhalers in experienced adults. Ann Allergy Asthma Immunol 2004;93(5): 439-446.

28. Kamps AW, Brand PL, Roorda RJ. Determinants of correct inhalation technique in children attending a hospital-based asthma clinic. Acta Paediatr 2002;91(2):159-163.

29. Cain WT, Cable G, Oppenheimer JJ. The ability of the community pharmacist to learn the proper actuation techniques of inhaler devices. J Allergy Clin Immunol 2001;108(6):918-920.

30. Chopra N, Oprescu N, Fask A, Oppenheimer J. Does introduction of new "easy to use" inhalational devices improve medical personnel's knowledge of their proper use? Ann Allergy Asthma Immunol 2002; 88(4):395-400.

This article is approved for Continuing Respiratory Care Education credit. For information and to obtain your CRCE

(free to AARC members) visit www.RCJournal.com

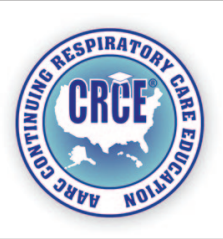

